\title{
2
}

\section{SMART CITIES AND THE POLITICS OF URBAN DATA}

\author{
Rob Kitchin, Tracey P. Lauriault and Gavin McArdle
}

\section{Introduction}

'Smart city' seems to be the urban buzzword for the 2010s. The ambition for just every city across the planet appears to be to become 'smarter'. Indeed, some nations have actively embraced the notion, with India, for example, announcing that it is to build 100 smart cities over the coming decades to accommodate a rapidly growing urban population (see Chapter 4). However, what constitutes a smart city is not universally agreed upon. In general terms, there are two main visions of smart urbanism, both of which are underpinned by the roll-out of new information and communication technologies (ICTs) and neoliberal visions of market-led and technocratic solutions to city governance and development, and are promoted as pragmatic, non-ideological and commonsensical in approach (Kitchin, 2014a).

On the one hand, a smart city is one whose urban fabric is increasingly instrumented, composed of 'everyware' (Greenfield, 2006) - software-enabled infrastructures and networked digital devices and sensors that are used to augment urban management and governance. Here, a smart city is one that can be monitored, managed and regulated in real time using ICT infrastructure and ubiquitous computing that generate big data (Townsend, 2013). On the other hand, a smart city is one whose economy is increasingly driven by technology-inspired innovation and entrepreneurship that, in turn, will attract businesses and jobs, create efficiencies and savings and raise the productivity and competitiveness of government and businesses (Caragliu et al., 2009). Here, the focus is on the formulation and adoption of policies that use ICT to reshape human capital, creativity, education, sustainability, governance and economic activity to produce knowledge-driven, competitive, resilient urban systems. In many cases, cities are pursuing becoming smart in both regulatory and economic terms.

Whilst the creation of smart cities has many supporters, most notably governments that hope to address and manage the many issues cities face using 
ICT-based solutions and businesses that seek to profit from selling new smart city technologies and services, smart urbanism has not been universally welcomed. Indeed, a number of critical scholars and community activists have challenged the prevailing rhetoric and have sought to unpack, contextualise and make sense of smart city initiatives (Hollands, 2008; Greenfield, 2013; Vanolo, 2014; Datta, 2015), or develop a more inclusive notion of a smart city (Hill, 2013; Townsend, 2013). This chapter examines five critiques of smart cities in broad terms, followed by a more sustained discussion of one of these critiques, namely the politics of urban digital data and the development of urban indicators, city benchmarking and real-time dashboards and their use in urban governance. Such a focus on urban digital data is important because its generation, exchange and analysis is central to the production of smart urbanism: the material that networked ICT systems process and from which they create and extract value. The key thrust of the argument developed is that whilst the smart city technologies and initiatives are generally portrayed and positioned as technical, pragmatic, commonsensical and non-ideological - that is, as rational interventions designed to improve social, economic and governance systems - they are inherently politically and ideologically loaded in vision and application, reshaping in particular ways how cities are managed and regulated. Likewise, the data within these systems are not neutral and objective in nature, but are situated, contingent and relational, framed by the ideas, techniques, technologies, people and contexts that conceive, produce, process, manage, analyse and store them (Bowker and Star, 1999; Lauriault, 2012; Ribes and Jackson, 2013). Drawing on our analysis of indicators, benchmarking and dashboards, we contend that the politics and technical and epistemological shortcomings of smart city initiatives need to be exposed and critiqued, not necessarily to call for them to be abandoned, but rather so they can be reimagined and repositioned in more inclusive, open and relational ways.

\section{Five critiques of smart cities}

There is a powerful political and economic lobby advocating the development of smart cities. The arguments forwarded by this lobby propose that smart city initiatives will lead to more efficient, effective, sustainable, resilient, safe and secure cities. This has been countered by critical scholars, policy analysts and community organisations, whose concerns can be divided into five broad themes: the growth of technocratic governance; the hollowing out of the state and the corporatisation of city governance; the creation of buggy, brittle and hackable city systems; the production of panoptic surveillance, predictive profiling and social sorting; and the promotion of an instrumental rationality and realist epistemology.

\section{Technocratic governance}

The first major concern about smart cities is that they adopt and promote technocratic forms of governance that presume that all aspects of a city can be measured, 
monitored and treated as technical problems that can be addressed through technical solutions. Such an approach is underpinned by what Mattern (2013) terms 'instrumental rationality' and practices what Morozov (2013) calls 'solutionism'. That is, there is a belief that complex open systems can be disassembled into neatly defined problems that can be solved or optimised through computation. All that is required to understand, manage and fix - in rational, logical and impartial ways - the issues a city faces is sufficient data and suitable algorithms. The critique of such an approach is threefold. First, a technocratic approach is highly reductionist and functionalist, always based on a limited selection of data and shaped by the formulation of algorithms, and fails to recognise the wider effects of culture, politics, policy, governance and capital in shaping city life and urban systems. Second, technological solutions largely focus on the efficient management of the manifestations of problems, rather than solving the deep-rooted structural problems underpinning them. As such, they largely paper over cracks rather than fixing them, unless coupled with a range of other policies. Third, technocratic control and command systems tend to centralise power and decision-making into a select set of administrative offices, rather than distributing power. Consequently, it is suggested that smart city initiatives will produce anaemic forms of top-down, centralised governance that do not live up to their promise.

\section{Corporatisation of governance}

The second concern is that, as well as being too technocratic in nature, the smart city agenda is being overly driven by corporate interests who are using it to capture government functions as new market opportunities (Greenfield, 2013; Townsend, 2013). Several of the world's largest digital technology and consulting companies operate smart city initiatives, including IBM, Cisco, Intel, Microsoft, SAP and Arup, and have become active players in city management, either through being key partners in building new smart cities from the ground up (e.g. Songdo or Masdar City), or partnering with established cities to retrofit their infrastructure with ICT and data solutions. While such companies might be fostering innovative and useful interventions there are three related anxieties concerning their foray into roles traditionally delivered by the state, especially those involving regulation and governance. First, it actively promotes a neoliberal political economy, the marketisation of public services and the hollowing out of the state, wherein city functions are administered for private profit (Hollands, 2008). Second, it potentially creates a technological lock-in or corporate path dependency that tie cities to particular technological platforms and vendors over a long period of time, creating monopoly positions (Hill, 2013). Third, it will lead to the creation of 'one size fits all smart city in a box' solutions that take little account of local cultures or political structures (Townsend et al., 2011).

\section{Buggy, brittle and hackable urban systems}

The third major concern is that the ubiquitous use of digital technologies for running and managing city services and infrastructures is creating environments which 
are inherently buggy and brittle and are prone to viruses, glitches, crashes and security hacks (Kitchin and Dodge, 2011; Townsend, 2013). Technologies powered by software constitute an unusual product because they are sold in full knowledge that they are inherently partial, provisional, porous and open to failure. Such technologies routinely have to be patched and updated to cope with new contingencies. Further, they are vulnerable to being maliciously hacked, with the system subverted or shut down or valuable data stolen. As systems become ever more complicated, interconnected and dependent on software, producing stable, robust and secure devices and infrastructures becomes more of a challenge (Townsend, 2013). The notion of smart cities takes two open, highly complex and contingent systems - cities and digital systems - and binds them together. At the same time, these new systems lead to the discontinuation of analogue alternatives, meaning that if they fail there are no alternatives until the system is fixed/rebooted. The fear for some commentators is the creation of highly vulnerable and costly urban systems, rather than robust systems that create efficiencies and resilience.

\section{Panoptic surveillance, predictive profiling and social sorting}

Smart city technologies generate and are dependent on vast quantities of data. Many are the sources of what has been termed big data. That is, datasets that are: generated in real time; exhaustive rather than sampled; varied in nature; fine-grained in resolution; uniquely indexical in identification; relational; and flexible, holding the traits of extensionality (can add new fields easily) and scalability (can expand in size rapidly) (Kitchin, 2014b). Digital CCTV, retail checkout tills, smart phones, online transactions and interactions, sensors and scanners and social and locative media - produced by government agencies, mobile phone operators, app developers, internet companies, financial institutions, retail chains and surveillance and security firms - all generate massive amounts of detailed data about cities and their citizens. Such data are being routinely traded to and between data brokers as an increasingly important commodity, and examined by state security and policing agencies. For many commentators, the creation of smart cities raises questions concerning the creation of panoptic surveillance (gazing at the world) and wide-scale dataveillance (trawling through and interconnecting datasets), as well as anxieties relating to predictive profiling, social sorting and anticipatory governance that use data and algorithms to determine how people are treated (Kitchin, 2014b). The fear is that, far from being a liberatory and empowering development, smart cities may well lead to highly controlling and unequal societies in which rights to privacy, confidentiality, freedom of expression and life chances are restricted.

\section{The politics of urban data}

The final concern, and the focus of the rest of this chapter, is the politics of urban data. As already noted, the generation, processing and analysis of data is critical to 
TABLE 2.1 The apparatus and elements of a data assemblage

\begin{tabular}{|c|c|}
\hline Apparatus & Elements \\
\hline Systems of thought & $\begin{array}{l}\text { Modes of thinking, philosophies, theories, models, } \\
\text { ideologies, rationalities, etc. }\end{array}$ \\
\hline Forms of knowledge & $\begin{array}{l}\text { Research texts, manuals, magazines, websites, } \\
\text { experience, word of mouth, chat forums, etc. }\end{array}$ \\
\hline Finance & $\begin{array}{l}\text { Business models, investment, venture capital, grants, } \\
\text { philanthropy, profit, etc. }\end{array}$ \\
\hline Political economy & $\begin{array}{l}\text { Policy, tax regimes, incentive instruments, public and } \\
\text { political opinion, etc. }\end{array}$ \\
\hline Governmentalities and legalities & $\begin{array}{l}\text { Data standards, file formats, system requirements, } \\
\text { protocols, regulations, laws, licensing, intellectual } \\
\text { property regimes, ethical considerations, etc. }\end{array}$ \\
\hline Materialities and infrastructures & $\begin{array}{l}\text { Paper/pens, computers, digital devices, sensors, } \\
\text { scanners, databases, networks, servers, buildings, etc. }\end{array}$ \\
\hline Practices & $\begin{array}{l}\text { Techniques, ways of doing, learned behaviours, } \\
\text { scientific conventions, etc. }\end{array}$ \\
\hline Organisations and institutions & $\begin{array}{l}\text { Archives, corporations, consultants, manufacturers, } \\
\text { retailers, government agencies, universities, } \\
\text { conferences, clubs and societies, committees and } \\
\text { boards, communities of practice, etc. }\end{array}$ \\
\hline Subjectivities and communities & $\begin{array}{l}\text { Of data producers, experts, curators, managers, } \\
\text { analysts, scientists, politicians, users, citizens, etc. }\end{array}$ \\
\hline Places & $\begin{array}{l}\text { Labs, offices, field sites, data centres, server farms, } \\
\text { business parks, etc., and their agglomerations }\end{array}$ \\
\hline Marketplace & $\begin{array}{l}\text { For data, its derivatives (e.g. text, tables, graphs, maps), } \\
\text { analysts, analytic software, interpretations, etc. }\end{array}$ \\
\hline
\end{tabular}

Source: Kitchin (2014b: 25)

smart city initiatives. To be smart, that is to act with wisdom, one requires knowledge, which is dependent on information, which is extracted from data. As with smart city projects themselves, the data they rely on are portrayed as being objective and non-ideological. How can a sensor, a smartphone or a commercial transaction have a politics? They simply measure light or heat or app use or a trade - producing measurements and records that reflect the truth about the world. Data can thus be taken at face value. Likewise, it is argued, the algorithms used to process these data are neutral and non-ideological in their formulation and operation, grounded in scientific objectivity. Such a framing of data and algorithms enables smart city projects to present an image of being politically benign and commonsensical; that they help make a city secure, efficient, productive, sustainable and so on, by employing rigorous, technical practices that capture, process and analyse vast quantities of transparent, neutral, objective data.

Critics, however, contend that data are much more complicated in nature (Kitchin, 2014b). What data are generated is the product of choices and constraints, 


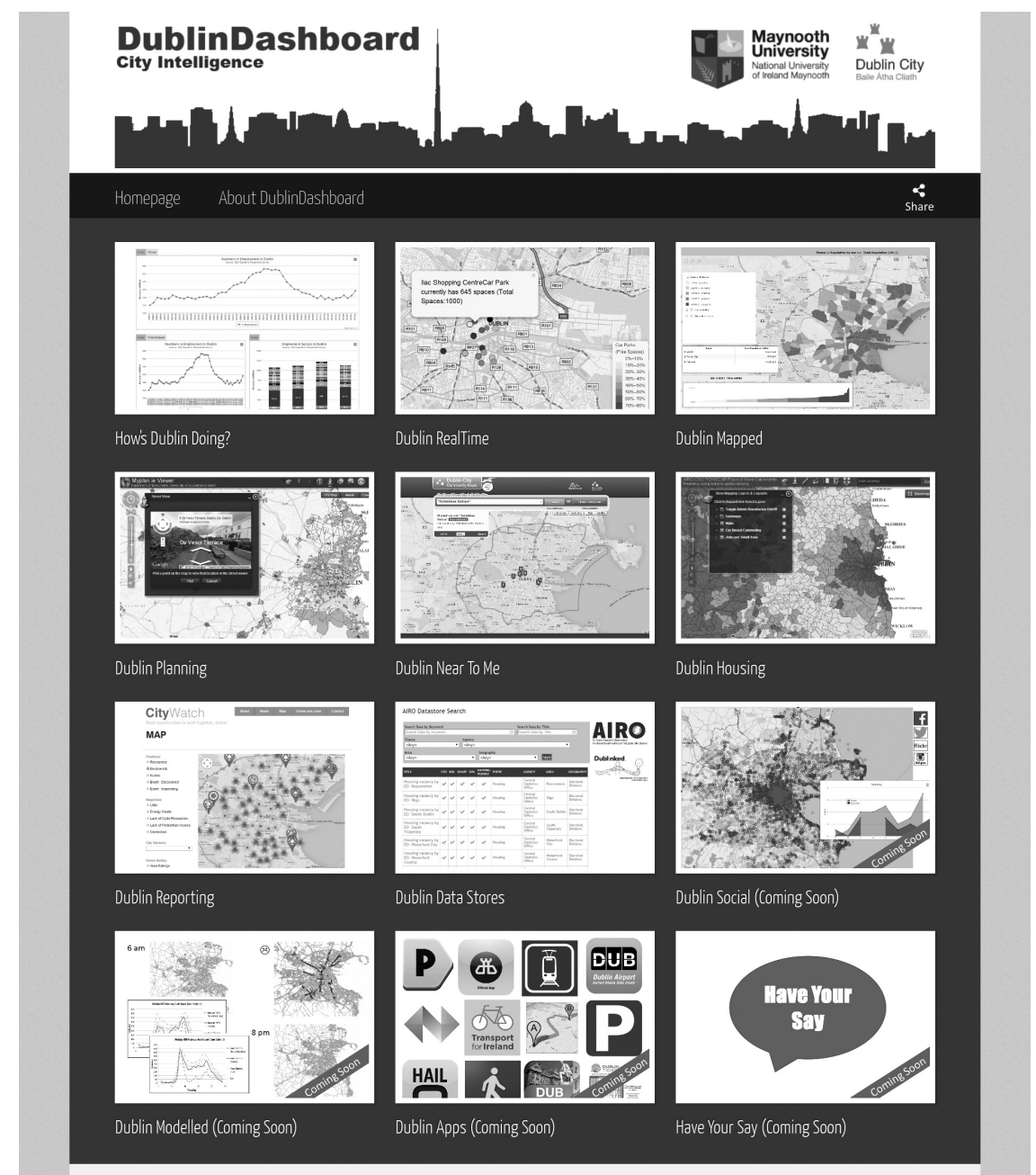

FIGURE 2.1 Dublin Dashboard

Source: www.dublindashboard.ie (used with permission)

shaped by a system of thought, technical know-how, public and political opinion, ethical considerations, the regulatory environment and funding and resourcing. What data are captured by a system is shaped by: the field of view/sampling frame (where data-capture devices are deployed, what their settings/parameters are, who uses a space or media); the technology and platform used (such as different surveys, sensors, lenses, textual prompts and layout, which produce variances and biases in what data are generated); the context in which data are generated (unfolding events mean data are always situated and contextualised with respect to circumstance); the data ontology employed (how the data are calibrated and classified); and the regulatory environment with respect to privacy, data protection and security (Kitchin, 
2013). Data are situated, contingent, relational and framed and used contextually to try and achieve certain aims and goals. They are the product of a complex data assemblage (see Table 2.1).

This notion of a data assemblage is similar to Foucault's (1977: 194) concept of the 'dispositif' - a 'thoroughly heterogeneous ensemble consisting of discourses, institutions, architectural forms, regulatory decisions, laws, administrative measures, scientific statements, philosophical, moral and philanthropic propositions', which enhance and maintain the exercise of power within society. The dispositif of a data assemblage produces what Foucault terms 'power/knowledge', that is, knowledge that fulfils a strategic function. Such assemblage thinking, extended and reworked into a diverse set of post-structural and materialist mappings of both relational ontologies and the more flat ontologies of actor network theory, has been in recent years applied to urban studies (e.g. Farías and Bender, 2009; McGuirk and Dowling, 2009; McFarlane, 2011). Whatever the flavour of assemblage thinking, through such lenses it is clear that data are produced, managed, shared and deployed within heterogeneous ensembles which are never neutral, essential and objective in nature data are never raw but always cooked to some recipe by chefs embedded within institutions that have certain aspirations and goals and operate within wider frameworks and constraints.

It is the tension between the realist epistemology (data show the city as it actually is) and the instrumental rationality of smart city systems, and an alternative view that exposes the politics and assemblages of such data and systems, that the rest of the chapter considers. It does so by critically examining urban indicator, city benchmarking and real-time dashboard projects, which are considered key municipal initiatives for enacting smarter governance. The analysis presented draws on an extensive reading of the literature and reflection on our own work building the Dublin Dashboard (see Figure 2.1), which blends indicators, benchmarks and dashboards into one extensive open-access data system for the city.

\section{Urban indicators, city benchmarking and real-time dashboards}

Urban indicators are recurrent quantified measures that can be tracked over time to provide a picture of stasis and change with respect to urban phenomenon. A number of different indicator types can be deployed, which vary in their rationale and use. Single indicators consist of the measurement or a statistic related to a single phenomenon. Such indicators can be direct (e.g. measuring the phenomenon, such as $\mathrm{R} \& \mathrm{D}$ spend to reflect investment in innovation) or indirect (e.g. using a proxy, such as the number of patents registered) in nature. Composite indicators combine several single measures using a system of weights or statistics to create a new derived measure, recognising that most phenomena (e.g. social deprivation) are interrelated and multidimensional and that no one indicator can reveal the extent or complexities underpinning an issue (Maclaren, 1996). Single and composite indicators can be deployed in different ways as: 
- descriptive or contextual indicators that provide overviews of phenomena and allow comparison between locales that form inputs into policy formulation, but are not used in prescriptive or disciplining ways;

- diagnostic, performance and target indicators that are used to diagnose a particular issue or assess performance such as effectiveness (whether goals and objectives are being met - doing the right things) and efficiency (whether getting the most output for the input - doing things right and value for investment) of a policy or programme, individual workers, departments, organisations and sectors (Holden, 2006; Franceschini et al. 2007). Targets can be absolute (to reach a defined level) or relative (to match the performance of another organisation/ place);

- $\quad$ redictive and conditional indicators that are not only considered good measures of present trends, but also key referents for predicting and simulating future scenarios and performances.

The most prized indicators are those that are considered well defined and unambiguous, are independent of external influence, have strong representativeness (they measure what they claim to measure), can be easily captured as a quantitative measure, are traceable over time, sensitive to change, verifiable and replicable, easy to interpret, timely (produced regularly and reported with minimal delay) and quick and cost-effective to collect, process and update (Franceschini et al., 2007; Bhada and Hoornweg, 2009).

Urban indicator projects have proliferated since the early 1990s, driven by the sustainability goals of the United Nations Conference on Environment and Development (UNCED) in Rio de Janeiro in 1992 and in particular Chapter 40 of Agenda 21, and the rise of new managerialism and the desire to reform the public sector management of city services to make them more efficient, effective, transparent and value for money, combined with citizen and funder demands for evidence-based decision-making. As a consequence, cities around the world now routinely generate suites of indicator data, using them to track and trace performance, guide policy formulation and to inform how cities are governed and regulated. Indeed, in many locales, the use of urban indicators has become normalised as the de facto civic epistemology through which a public administration is measured and performance communicated (Miller, 2005). Further, indicators can be used as the inputs to urban models that seek to explain present patterns, and simulate and predict what might happen under different circumstances.

City benchmarking consists of comparing urban indicators within and across cities to establish how well an area/city is performing vis-à-vis other locales or against best practice. The process is often accompanied with score-carding, whereby tables of rankings and ratings, along with changes in relative position, are produced to reveal which places are doing well and who has caught up or fallen behind leading places (Gruppa and Mogee, 2004). Huggins (2009) details three types of area-based benchmarking: performance benchmarking that compares how well a place is doing with respect to a set of prescribed indicators; process benchmarking 
that compares the practices, structures and systems of places; policy benchmarking that compares public policies that influence performance and processes with respect to outcomes and meeting prescribed expectations. Benchmarking sets an aspirational and competitive agenda for cities and are used to motivate policy changes deemed necessary to alter a city's relative rating/ranking. When a city is relatively highly ranked, the scores are often also used in place-promotion to attract foreign direct investment and tourists. Jones Lang LaSalle report that there are now over 150 city benchmarking initiatives which seek to compare and contrast hundreds of cities (Moonen and Clark, 2013). In 2014, an ISO standard for city benchmarking indicators was announced (ISO, 2014a), designed to produce standardised, reputable, verifiable comparable global urban data (ISO, 2014b).

Dashboards visualise indicators through a graphic interface and are common sights in urban control rooms. Some dashboards seek to consolidate critical information onto a single screen using visualisation techniques such as gauges, traffic-light colours, meters, arrows, bar charts and graphs, which can be monitored at a glance (Few, 2006; see Figure 2.2). In contrast, analytical dashboards provide more extensive systems, acting as a console for navigating, drilling down into, visualising and making sense of numerous layers of interconnected data (Dubriwny and Rivards, 2004; see Figure 2.1). Dashboards are usually interactive, enabling users to interrogate and play with the data. Often, data can be simultaneously visualised in a number of ways, for example as a table, graph and map, with interactions in one pane being mirrored in the others. Dashboards thus provide a 'span of control' over a large repository of voluminous and varied data, and quickly transitioning data in the case of real-time data (Brath and Peters, 2004). As such they enable domains to be explored and interpreted without the need for specialist analytics skills (the systems are point and click and require no knowledge of how to produce graphics or maps). The power of dashboards is that they quickly and effectively provide city managers and to a lesser extent citizens with up-to-date detailed information about different aspects of urban systems and milieux, and how they are changing over time and space.

For their advocates, indicator, benchmarking and dashboard initiatives have high utility because they reveal in detail the state of play of cities. They enable a city to be known as it actually is and to assess how it is performing vis-à-vis targets and other places. They thus provide a powerful realist epistemology that shapes not only how cities are understood, but how cities are managed and governed. How such projects are translated into governance strategies, techniques and structures, however, varies between places.

For some municipalities, indicator, benchmarking and dashboard initiatives are being used to underpin forms of new managerialism. In such cases, they are used to guide operational practices with respect to specified targets, provide evidence of the success or failure of programmes and policies, discipline and reward performance and guide the development of new strategies (Craglia et al., 2004). Just as the dashboard of an aircraft cockpit provides detailed data about a plane and its flight, such projects are understood to provide city managers with data about the city and its management (Edwards and Thomas, 2005). Within such a framework, cities 


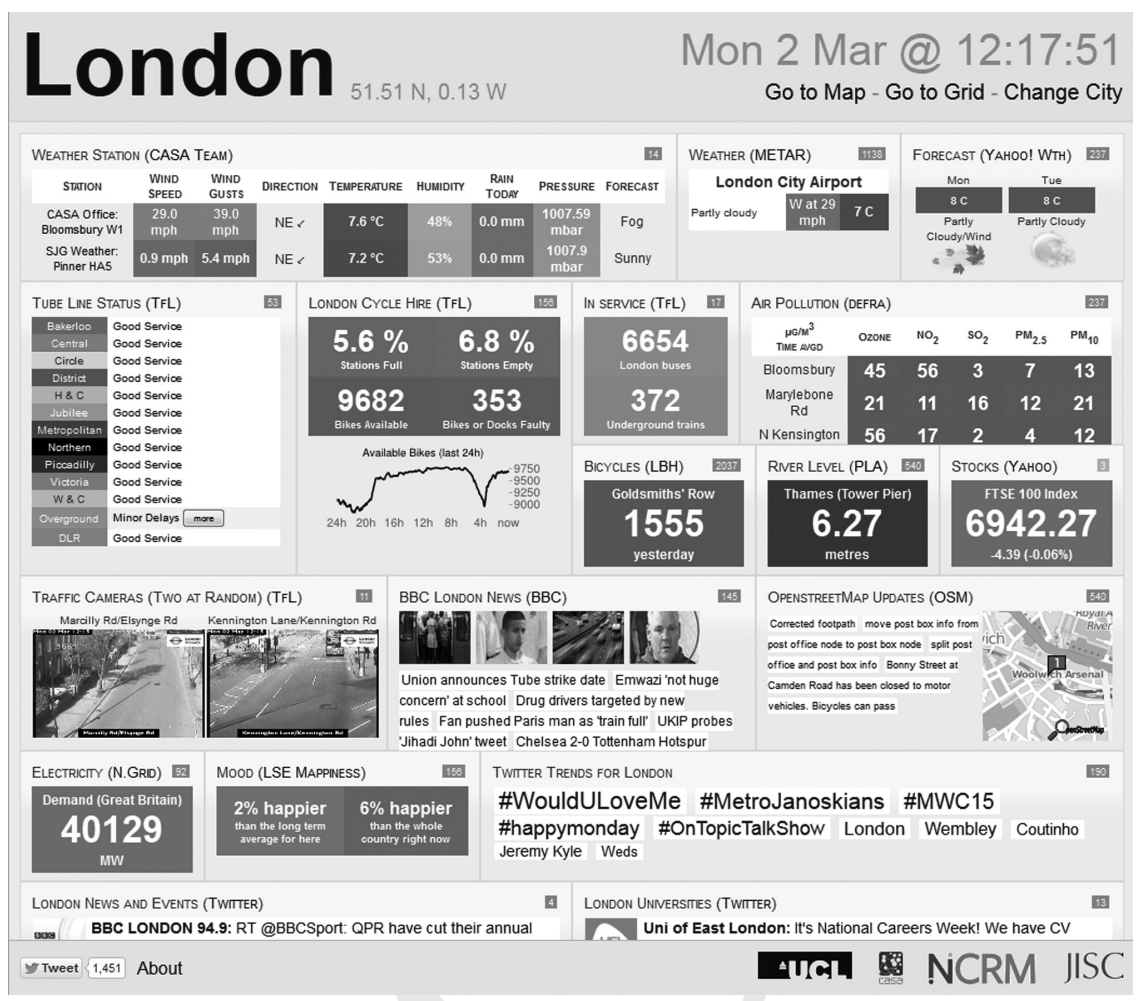

FIGURE 2.2 CASA London Dashboard

Source: citydashboard.org/london/ (used with permission)

are understood to consist of a set of knowable and manageable systems that act in 'rational, mechanical, linear and hierarchical' ways and 'can be steered and controlled with strong leadership, solid coordination, powerful (planning) instruments and/or high-quality guidance information' (Block and Van Assche, 2010: 3). There is thus a strong degree of instrumental rationality at play. An example of such an approach is Baltimore's use of CitiStat. Every week city managers meet in a specially designed room using dashboards to review performance and set new targets for the city as a whole and for each department (Gullino, 2009).

In contrast, some municipalities use indicators, benchmarking and dashboards in a more contextual way. Rather than cities being understood as mechanical systems that can be disassembled into their component parts and fixed, or steered and controlled through data levers, cities are conceived as consisting of multiple, complex, interdependent systems that influence each other in often unpredictable ways (Innes and Booher, 2000). Moreover, governance is seen as being complex and multi-level in nature, and the effects of policy measures are diverse and multifaceted, and neither is easily reducible to performance metrics and targets. Indicators highlight trends and potential issues, but do not show their causes or prescribe answers. 
Deriving solutions to the issues facing cities then requires more than simply pulling levers in response to changes in indicator patterns. In such cases, indicators, benchmarking and dashboards are seen as one set of useful contextual data, but are not used in a strongly instrumentalist, mechanistic way to direct management practices. A long-standing example of such an approach is that employed within Flanders, Belgium, where since the late 1990s a number of cities have employed a common City Monitor for Sustainable Urban Development, consisting of nearly 200 indicators, to provide contextual evidence for policy-making (Block and Van Assche, 2010; Van Assche et al., 2010). The Dublin Dashboard follows this model.

In both new managerialism and contextual policy formulation, indicator, benchmark and dashboard projects form key initiatives in trying to implement more data-driven, evidence-based practices of governance and policy formulation. Their realist epistemology is favoured over more subjective and qualitative forms of information, because they provide objective, neutral facts that enable transparent, non-political, commonsensical policy- and decision-making. Not only does this provide better intelligence, it counters policy based on anecdote, cronyism and localism. However, such projects are far from being non-political, commonsensical and objective, as we now discuss.

\section{The politics of indicator, benchmarking and dashboard initiatives}

Indicator data supposes that facts can be abstracted from the world in value-free and objective ways and be benchmarked against each other. A fact is after all a fact and can be accurately measured - there are $x$ number of people living in a city; $x$ percentage of them are unemployed; there are $x$ number of deaths from different illnesses; the trains are on average $x$ minutes late, etc. In some cases, these facts can be measured using scientific instruments or algorithms mining databases; in others, by means of opinion surveys. In the latter case, it is assumed that a form of mechanical objectivity is deployed that adheres to defined rules and rigorous, systematic method to produce distant, detached, impartial and transparent data that are free of researcher bias and preferences, and are independent of local customs, culture, knowledge and context (Porter, 1995). Indicator and benchmark data can thus be accepted at face value as expressing a truth about the world (Kitchin, 2014a) and deployed through an instrumental rationality (Mattern, 2014).

As already noted, however, critics contend that a fact is never simply a fact. Facts are produced, not simply measured. How the rate of unemployment is calculated differs across locales (which one is 'true'?). It can often change within a jurisdiction, evolving through several iterations. Famously, the Thatcher Conservative government of the 1980s in Britain altered how unemployment was calculated twenty times in the space of a few years. When calculating how many people live in a city at any one time, who is selected for inclusion (e.g. are seasonal migrant workers included) and where is the boundary of a city (e.g. how much of its suburbs and hinterland 
are included)? Procedures and protocols, measurement instruments and scales, and standards used to generate facts are designed, negotiated and debated. Moreover, the production of facts is highly reductionist, atomising complex, contingent relationships into simplified, one-dimensional or composite measures. Reducing the city to a collection of facts decontextualises it from its history, its political economy, the wider set of social, economic and environmental relations that frame its development and its interconnections and interdependencies that stretch out over space and time (cities are open, not closed systems; Craglia et al., 2004; Mori and Christodoulou, 2012). It thus produces a very particular, shallow representation of the city. Consequently, how data are ontologically defined as facts is not a neutral, technical process, but a normative, political and ethical one (Bowker and Star, 1999).

Further, such initiatives tend to gloss over technical issues that also undermine their supposed objectivity. As with all data, because indicator data are abstracted and representative there are always questions concerning data veracity and quality. These questions extend to how accurately (precision) and faithfully (fidelity) the data represent what they are meant to (especially when using samples and proxies), and how clean (error- and gap-free), untainted (bias free), consistent (few discrepancies) and reliable (the measurement instrument consistently produces the same quality of results) the data are (Goodchild, 2009; Kitchin, 2014a). The level of data trustworthiness also varies over time and place due to different measurement regimes and their evolution, as new technologies, practices and personnel are deployed (Ribes and Jackson, 2013). There are also ecological fallacy effects created through strategies such as aggregation. For example, indicator values often represent large, diverse areas masking internal variation that can lead to false conclusions being drawn about a place as a result of how the underlying data are collated, categorised and presented. As a consequence, decisions over the statistical geography of a city can have a dramatic effect on indicator values and benchmarking ranking (Openshaw, 1984; Wrigley, 1995). Similarly, altering the relative weightings of data in composite indicators can have a profound effect on the resulting score. Indeed, many composite indicators are highly sensitive to adjustments and thus are vulnerable to manipulation, either through tinkering with the algorithm or by gaming the data (Gruppa and Mogee, 2004). Interpreting indicator data always requires, then, an appreciation of the level of uncertainty inherent in the data and analysis effects.

These various issues undermine the credibility of benchmarking initiatives which assume a universalism in the validity and standard of measures and method across place. Benchmarking also assumes that there is a normative standard by which places should be judged, some ideal state they are all seeking to achieve, rather than acknowledging that phenomenon in different jurisdictions/places differ from one another often for good reasons (they have different aims, ambitions, histories, economies, etc.), and that how indicators relate to policy-making in one place may produce poor policy in another (Gruppa and Mogee, 2004; Huggins, 2009). Moreover, benchmarking is a zero-sum game in that cities are rated and ranked, with only one city being able to occupy each place, so that despite the fact that they may have improved their performance they are still lowly ranked vis-à-vis other locales. 
The use of dashboards has been an important factor in the promotion of indicator and benchmarking initiatives because they provide a powerful means to make sense of such data (through time and across space). Dashboards facilitate the illusion that it is possible to 'picture the totality of the urban domain', to translate the messiness and complexities of cities into rational, detailed, systematic, ordered forms of knowledge (Mattern, 2014: online). Dashboards, however, do not simply present the data.They too have a politics. Their makers might envisage them as detached, passive or neutral instruments that communicate the world as it is, but dashboards actively frame and do work in the world. They do not simply represent urban phenomena, but are constitutive of and actively produce meaning. As such, a dashboard seeks to act as a translator, not simply a mirror, setting the forms and parameters for how data are communicated and thus what the user can see and engage with. This translation is ideologically framed and inherently political, shaping what questions can be asked of the underlying data and what answers can be obtained.

Indicator, benchmarking and dashboard initiatives thus inherently express a normative notion about what should be measured and how it should be measured. They are full of values, judgements and deliberate strategies of occlusion. And the decisions taken have consequence for subsequent analysis, interpretation and action. Further, indicator, benchmarking and dashboard initiatives have a deep normative effect, being used to shape city governance, modify institutional behaviour, condition workers, influence decision-making and shape spending patterns (Franceschini et al., 2007). In this sense, they do not simply act as a camera reflecting the world as it is, but rather act as an engine shaping the world in diverse ways (MacKenzie, 2008). They not only represent urban systems, but actively help produce them. As Hezri (2004) details, indicators can be used in many different ways that are all politically charged: instrumentally (e.g. for problem-solving and decision-making); conceptually (e.g. to understand and interpret a situation); tactically (e.g. for delaying a strategy, to substitute for action, deflect criticism); symbolically (e.g. to provide reassurance or place promotion); and politically (e.g. as ammunition to support a particular position).

These politics and technicalities of indicator and benchmarking data and dashboards are framed and produced by their associated data assemblage. For example, with respect to the Dublin Dashboard, there were several internal team meetings and meetings with public officials concerning the purpose and principles of the dashboard, the selection of indicators and modules, obtaining access to data sources, dashboard design, selection of software, roll-out and use of the system, future maintenance and so on. Each issue was debated and consensus established, framed within the wider context of the systems of thought, ideologies and communities of practice of the developers and city officials; their knowledge base of data relating to the city, the handling, analysing and displaying of such data and coding skills; the financial constraints of the project and the wider political economy, policy regime, governmentalities and legalities; the materials and infrastructures available to them; and so on (see Table 2.1). In other words, there was nothing inevitable about the scope, form, and operation of the Dublin Dashboard, nor the qualities of the data 
presented through it; instead they emerged through design, tinkering and debate and negotiation between stakeholders, framed with a wider assemblage of ideas, institutions, policies, regulations, laws, finance, etc.

\section{Conclusion}

Since 2010 and the launch of IBM's smarter cities challenge, there has been a growing call from business, government and academia for the creation of smart cities. This call seeks to build on the roll-out of networked urbanism and the embedding of digital technologies into the fabric of cities over the next couple of decades. The result is a powerful discursive regime that promotes the vision of smart urbanism cities that seek to leverage digital technologies to produce secure, efficient, productive, competitive, sustainable, resilient urban locales. The smart city is forwarded as the most effective way of coping with the projected enormous growth in urban populations, adapting to climate change and other environmental shocks and enabling efficiencies whilst coping with shrinking public budgets. For the most part, the creation of smart cities is presented as a pragmatic, non-ideological, commonsensical approach to dealing with the various issues facing cities. However, as we have discussed in this chapter, such a claim is disingenuous and there are a number of unresolved concerns about the development of smart cities. These include anxieties related to the rise in technocratic governance, the corporatisation of governance, the creation of buggy, brittle and hackable systems, panoptic surveillance, predictive profiling and social sorting and the politics of urban data.

This chapter has largely concentrated on examining the latter by considering the roll-out of indicator, benchmark and dashboard initiatives, which constitute one set of smart city technologies. These initiatives purport to provide detailed city intelligence, including real-time overviews of how the city is performing. Their power is derived from a realist epistemology that claims to show the city as it actually is, along with an instrumental rationality that translates factual information into actionable knowledge. As a consequence, such initiatives have quickly become key technologies in how many cities are managed and governed, though how they are conceived and deployed can vary quite markedly. We have sought to trouble this epistemology and rationality by exposing their politics and technical issues, demonstrating that their claims to 'truth' are little more than claims. Instead, such initiatives are framed by and within wider data assemblages and are plagued by technical and methodological conundrums. They are the outcome of normative concerns and they have normative effects.

Nonetheless, we are of the view that indicator and dashboard projects have utility, providing information of value to city managers and citizens. Such initiatives provide valuable spatially extensive and time-series data about the state of play of cities. They provide an evidence base far superior to anecdote, and have advantages over one-off studies in terms of coverage and regularity. Rather than being abandoned, instead we contend they need to be reimagined and positioned, openly 
recognising and acknowledging: (i) the multiple, complex, interdependent nature of cities, which means that they cannot be simply disassembled into a collection of facts; (ii) that indicators and dashboards do not merely reflect cities, but actively frame and produce them; (iii) that they are not mechanistic toolkits but data assemblages - complex socio-technical systems infused with politics and context; and (iv) that there are a multitude of other ways to see and understand the city that produce valuable, insightful knowledge.

It may well be the case that those who develop and promote indicator, benchmark and dashboard initiatives are already aware of their contingencies, relationalities, politics and technical shortcomings, but deal with them by engaging in a form of strategic essentialism that covers them over or pretends they do not exist in order to promote their approach (and in the case of industry, products) and to deflect possible critique. If this is the case, then we are advocating that the fig-leaf of such strategic essentialism be tugged away. The stakes with regards to how cities are managed and governed using such initiatives are too high - particularly when they are used to direct resources and formulate and implement policy. This is the approach we have taken in the Dublin Dashboard initiative, seeking to be reflexive as to how the project is framed, understood and practised within an assemblage of various actors and actants.

In our view such reimagining and repositioning needs to occur across smart city technologies. While they might be pragmatic approaches to the myriad issues facing cities, none of them is non-ideological and commonsensical. Instead they are all infused with politics and technical issues that need to be recognised and acknowledged. It is through such a strategy that more emancipatory and empowering visions of smart cities can be developed that best serve the common good and not simply the market ambitions of companies or the control desires of states.

\section{Acknowledgements}

The research for this chapter was funded by a European Research Council Advanced Investigator award (ERC-2012-AdG-323636-SOFTCITY) and Science Foundation Ireland.

\section{References}

Bhada, P. and Hoornweg, D. (2009) The Global City Indicators Program: A More Credible Voice for Cities. Washington, DC: World Bank, Urban Development Unit.

Block, T.andVan Assche, J. (2010) Disentangling urban sustainability: the Flemish City Monitor acknowledges complexity. Paper presented at the Seventh International Conference on Ecological Informatics: Unravelling Complexity and Supporting Sustainability, Ghent, Belgium, December 2010. Available at: https://biblio.ugent.be/input/download?func $=\mathrm{d}$ ownloadFile\&recordOId=1090655\&fileOId=1090661 [Accessed 17 July 2014).

Bowker, G. and Star, L. (1999) Sorting Things Out: Classification and Its Consequences. Cambridge, MA: MIT Press. 
Brath, R. and Peters, M. (2004) Dashboard design: why design is important. DM Direct, October 2004.

Caragliu, A., Del Bo, C. and Nijkamp, P. (2009) Smart Cities in Europe. Research Memoranda Series 0048. Amsterdam: VU University Amsterdam, Faculty of Economics, Business Administration and Econometrics.

Craglia, M., Leontidou, L., Nuvolati, G. and Schweikart, J. (2004) Towards the development of quality of life indicators in the 'digital' city. Environment and Planning B 31 (1): 51-64.

Datta, A. (2015) New urban utopias of postcolonial India: 'entrepreneurial urbanization' in Dholera smart city, Gujarat. Dialogues in Human Geography 5 (1): 3-22.

Dubriwny, D. and Rivards, K. (2004) Are you drowning in bi reports? Using analytical dashboards to cut through the clutter. DM Review, April 2004. Available at: www.advizorsolutions.com/press/Cut\%20Through\%20The\%20Clutter.pdf [Accessed 4 June 2014].

Edwards, D. and Thomas, J. C. (2005) Developing a municipal performance-measurement system: reflections on the Atlanta Dashboard. Public Administration Review 65 (3): 369-376.

Farías, I. and Bender, T. (eds) (2009) Urban Assemblages: How Actor-Network Theory Changes Urban Studies. London: Routledge.

Few, S. (2006) Information Dashboard Design: The Effective Visual Communication of Data. North Sebastopol, CA: O'Reilly.

Foucault, M. (1977). The confession of the flesh. In Power/Knowledge: Selected Interviews and Other Writings, 1972-1977, ed. C. Gordon. New York: Pantheon Books, 1980, pp. 194-228.

Franceschini, F., Galetto, M. and Maisano, D. (2007) Management by Measurement: Designing Key Indicators and Performance Measurement Systems. Berlin: Springer.

Goodchild, M. F. (2009) Uncertainty. In R. Kitchin and N.Thrift (eds) International Encyclopedia of Human Geography, vol. 12. Oxford: Elsevier, pp. 1-5.

Greenfield, A. (2006) Everyware: The Dawning Age of Ubiquitous Computing. Boston: New Riders.

Greenfield, A. (2013) Against the Smart City. New York: Do projects.

Gruppa, H. and Mogee, M. E. (2004) Indicators for national science and technology policy: how robust are composite indicators? Research Policy 33 (9): 1373-1384.

Gullino, S. (2009) Urban regeneration and democratization of information access: CitiStat experience in Baltimore. Journal of Environmental Management 90: 2012-2019.

Hezri, A. A. (2004) Sustainability indicators system and policy processes in Malaysia: a framework for utilisation and learning. Journal of Environmental Management 73 (4): 357-371.

Hill, D. (2013). On the smart city: or, a 'manifesto' for smart citizens instead. City of Sound [online], 1 February. Available at: www.cityofsound.com/blog/2013/02/ on-the-smart-city-a-callfor-smart-citizens-instead.html [Accessed 5 February 2013]

Holden, M. (2006) Urban indicators and the integrative ideals of cities. Cities 23 (3): 170-183.

Hollands, R. G. (2008) Will the real smart city please stand up? Intelligent, progressive or entrepreneurial? City 12 (3): 303-320.

Huggins, R. (2009) Regional competitive intelligence: benchmarking and policy-making. Regional Studies 44 (5): 639-658.

Innes, J. and Booher, D.E. (2000) Indicators for sustainable communities: a strategy building on complexity theory and distributed intelligence. Planning Theory E Practice 1 (2): 173-186.

ISO (2014a) ISO 37120 Sustainable development of communities: indicators for city services and quality oflife [online].Available at: www.iso.org/obp/ui/\#iso:std:iso:37120:ed-1:v1:en [Accessed 8 October 2014].

ISO (2014b) How does your city compare to others? New ISO standard to measure up [online]. Available at: www.iso.org/iso/home/news_index/news_archive/news. htm?refid=Ref1848 [Accessed 17 July 2014]. 
Kitchin, R. (2013) Big data and human geography: opportunities, challenges and risks. Dialogues in Human Geography 3 (3): 262-267.

Kitchin, R. (2014a) The real-time city? Big data and smart urbanism. GeoJournal 79 (1): 1-14.

Kitchin, R. (2014b) The Data Revolution: Big Data, Open Data, Data Infrastructures and Their Consequences. London: Sage.

Kitchin, R. and Dodge, M. (2011) Code/Space: Software and Everyday Life. Cambridge, MA: MIT Press.

Lauriault, T. P. (2012) Data, infrastructures and geographical imaginations: mapping data access discourses in Canada. Unpublished $\mathrm{PhD}$ thesis, Carleton University, Ottawa.

McFarlane, C. (2011) The city as assemblage: dwelling and urban space. Environment and Planning D: Society and Space 29 (4): 649-671.

McGuirk, P. M. and Dowling, R. (2009) Neoliberal privatisation? Remapping the public and the private in Sydney's masterplanned residential estates. Political Geography, 28 (3): 174-185.

MacKenzie, D. (2008) An Engine, Not a Camera. How Financial Models Shape Markets. Cambridge, MA: MIT Press.

Maclaren, V. W. (1996) Urban sustainability reporting. Journal of the American Planning Association 62 (2): 184-202

Mattern, S. (2013) Methodolatry and the art of measure: the new wave of urban data science [online]. Design Observer: Places, 5 November. Available at: https://placesjournal.org/article/methodolatry-and-the-art-of-measure/38174/] [Accessed 15 November 2013].

Mattern, S. (2014) Interfacing urban intelligence [online]. Places: Design Observer, April. Available at: http://places.designobserver.com/feature/how-do-we-interface-with-sma rt-cities/38443/ [Accessed 17 July 2014].

Miller, C.A. (2005) New civic epistemologies of quantification: making sense of indicators of local and global sustainability. Science, Technology and Human Values 30 (3): 403-432.

Moonen, T. and Clark, G. (2013) The Business of Cities 2013: What Do 150 City Indexes and Benchmarking Studies Tell Us about the Urban World in 2013? Chicago: Jones Lang LaSalle. Available at: www.jll.com/Research/jll-city-indices-november-2013.pdf [Accessed 17 July 2014].

Mori, K. and Christodoulou, A. (2012) Review of sustainability indices and indicators: towards a new City Sustainability Index (CSI). Environmental Impact Assessment Review 32: 94-106.

Morozov, E. (2013) To Save Everything, Click Here: Technology, Solutionism, and the Urge to Fix Problems That Don't Exist. New York: Allen Lane.

Openshaw, S. (1984) The Modifiable Areal Unit Problem. Concepts and Techniques in Modern Geography 38. Norwich: Geo Books.

Porter, T. M. (1995) Trust in Numbers: The Pursuit of Objectivity in Science and Public Life. Princeton, NJ: Princeton University Press.

Ribes, D. and Jackson, S. J. (2013) Data bite man: the work of sustaining long-term study. In L. Gitelman (ed.) 'Raw Data' Is an Oxymoron. Cambridge, MA: MIT Press, pp 147-166.

Townsend, A. (2013) Smart Cities: Big Data, Civic Hackers, and the Quest for a New Utopia. New York: W.W. Norton.

Townsend, A., Maguire, R., Liebhold, M. and Crawford, M. (2011) A Planet of Civic Laboratories: The Future of Cities, Information and Inclusion. Palo Alto, CA: Institute for the Future.

Van Assche, J., Block, T. and Reynaert, H. (2010) Can community indicators live up to their expectations? The case of the Flemish City Monitor for Livable and Sustainable Urban Development. Applied Research Quality Life 5: 341-352. 
34 Kitchin, Lauriault and McArdle

Vanolo, A. (2014) Smartmentality: the smart city as disciplinary strategy. Urban Studies 51 (5): 883-898.

Wrigley, N. (1995). Revisiting the modifiable areal unit problem and the ecological fallacy. In A. D. Cliff, P. R. Gould, A. G. Hoare and N. J. Thrift (eds) Diffusing Geography: Essays for Peter Haggett. Oxford: Blackwell, pp. 49-71. 